\title{
Function and Health Status Outcomes Following Soft Tissue Reconstruction for Limb Preservation in Extremity Soft Tissue Sarcoma
}

\author{
Kristen M. Davidge, MD ${ }^{1,2}$, Jay Wunder, FRCSC ${ }^{3,4,5}$, George Tomlinson, PhD ${ }^{5,6}$, Rebecca Wong, FRCPC ${ }^{5,7}$, \\ Joan Lipa, FACS ${ }^{8}$, and Aileen M. Davis, PhD $^{2,5}$ \\ ${ }^{1}$ Division of Plastic and Reconstructive Surgery, University of Toronto, Toronto, Canada; ${ }^{2}$ Division of Outcomes and \\ Population Health, Toronto Western Research Institute, Toronto Western Hospital, Toronto, ON, Canada; ${ }^{3}$ Division of \\ Orthopaedic Surgery, Mount Sinai Hospital, Toronto, Canada; ${ }^{4}$ Department of Surgical Oncology, Princess Margaret \\ Hospital, Toronto, Canada; ${ }^{5}$ University of Toronto, Toronto, Canada; ${ }^{6}$ Division of Clinical Decision-Making and Health \\ Care, Toronto General Research Institute, Toronto, Canada; ${ }^{7}$ Department of Radiation Oncology, Princess Margaret \\ Hospital, Toronto, Canada; ${ }^{8}$ Division of Plastic and Reconstructive Surgery, UCLA, Los Angeles, CA
}

\begin{abstract}
Background. While advances in reconstructive surgery have facilitated limb preservation in extremity soft tissue sarcoma (ESTS), limited information exists as to the functional outcome of patients with these reconstructed extremities. The primary objective of this study is to evaluate the impact of flap reconstruction on postoperative function and health status in patients undergoing limbsalvage surgery for ESTS.

Methods. Clinical and outcome data for eligible patients were extracted from a prospectively maintained database of sarcoma patients. Four outcome measures were used to assess three domains of function (impairments, activity limitations, and participation restrictions), and health status. The effect of soft tissue reconstruction on function and health status at 1-2-year follow-up was analyzed using univariate and multivariate regression.

Results. Two hundred and forty-seven patients met eligibility criteria, including 56 patients receiving flap reconstruction and 191 patients treated with primary closure. Patients receiving flaps had larger $(9.8$ versus $7.1 \mathrm{~cm}$; $P=0.003$ ), higher-grade (93\% versus $72 \% ; P=0.001$ ) tumors, and more frequently received radiotherapy (89\% versus $72 \% ; P=0.007)$, and bone $(20 \%$ versus $4 \%$;
\end{abstract}

(C) Society of Surgical Oncology 2010

First Received: 13 July 2009

K. M. Davidge, MD

e-mail: kristen.davidge@utoronto.ca
$P=0.001)$ and motor nerve resection $(21 \%$ versus $10 \%$; $P=0.032)$. Flap reconstruction was associated with more postoperative impairments [Musculoskeletal Tumor Society (MSTS) score 30.4 versus 32.2; $P=0.004$ ] and activity limitations [Toronto Extremity Salvage Score (TESS) score 83.3 versus $89.5 ; P=0.0132]$ on univariate analyses, but did not significantly predict postoperative function or health status outcomes on multivariate analyses.

Conclusions. Flap reconstruction was not an independent predictor of function and health status outcomes in patients with ESTS. However, ESTS patients receiving flaps had other clinical features placing them at risk for worse postoperative outcomes.

Extremity soft tissue sarcomas (ESTS) are rare malignant neoplasms that account for up to $2 \%$ of all cancerrelated deaths. ${ }^{1,2}$ While patients with ESTS were historically treated by amputation, current multimodal approaches combining wide surgical resection with (neo)adjuvant radiotherapy and/or chemotherapy allow limb preservation in $90-95 \%$ of patients, without compromising disease recurrence and survival. ${ }^{3-10}$ However, managing tumors with a limb-salvage approach can create complex soft tissue defects susceptible to wound healing difficulties in the postoperative period. ${ }^{11,12}$ Reconstructive surgery in the form of pedicled and free tissue transfers has become paramount to the success of limb preservation in these difficult cases. Indeed, surgical flaps help to attain wound closure, fill surgical dead space, protect critical 
structures (i.e., nerves, tendons, joints), and promote wound healing. ${ }^{11-15}$

Although current evidence suggests that patients requiring soft tissue reconstruction for extremity salvage can achieve good oncologic outcomes, little is known regarding the function and quality-of-life outcomes of patients with these reconstructed extremities. ${ }^{16-18}$ Most prior research investigating function and health status in ESTS has focused on patients treated by simple wound closure techniques. ${ }^{5-21}$ Additionally, the small number of studies evaluating postoperative function in patients treated with extremity reconstruction are limited by small sample sizes and methodological approaches that fail to control for bias imparted by nonrandomization, lack of adjustment for confounders, and cross-sectional sampling. ${ }^{18,22-24}$

Importantly, no study has directly compared the function or health status outcomes of ESTS patients receiving soft tissue reconstruction versus primary wound closure for limb preservation. This information is necessary to inform patients regarding the risks and benefits of extremity reconstruction, as well as to manage patient expectations in the perioperative period. Furthermore, reconstructive techniques may themselves detrimentally affect function or quality-of-life outcomes in patients with ESTS, by harvesting healthy muscle tissue, delaying postoperative recovery, impairing use of clothing and footwear, and altering cosmesis. A better understanding of the impact of soft tissue reconstruction on function and health status is required to identify if and how reconstructive approaches can be modified to ultimately improve outcomes in this population.

The primary objectives of this study are therefore: (1) to compare postoperative function and health status in ESTS patients undergoing limb salvage with and without soft tissue reconstruction, and (2) to examine the effect of surgical flaps on function and health status at 1-2-year follow-up. Additionally, this study examined the relationship between soft tissue reconstruction and postoperative complications in ESTS patients undergoing limb-preserving surgery.

\section{PATIENTS AND METHODS}

This was a retrospective cohort study of ESTS patients undergoing limb-salvage surgery between September 2001 and July 2007 at two Canadian sarcoma centers (Toronto and Montreal). Study approval was obtained from the local ethics committee at each participating hospital, and informed consent was obtained from all participants. Patients were identified from a prospectively maintained database of extremity sarcoma patients and were classified into study groups according to the type of wound closure received at definitive limb-preserving surgery. The soft tissue reconstruction group included patients receiving pedicled or free flap reconstruction for extremity salvage. The primary closure group included patients in whom limb preservation was achieved by simple wound closure techniques, including direct skin approximation and splitthickness skin grafting (STSG).

Patients were eligible for inclusion if they were over 16 years of age, fluent in English or French, and presented with a primary or locally recurrent soft tissue sarcoma of the upper or lower extremity (as diagnosed by an approved reference pathologist). Disease-free patients with function and health status assessments at 12-24 months following definitive surgery were included. One year was chosen as the minimum follow-up, based on previous work in ESTS demonstrating a plateau in functional outcomes 6-12 months following limb-salvage surgery. ${ }^{25,26}$

Patients were excluded if they had concurrent malignancy, metastatic disease at presentation, or had received chemotherapy. Patients with atypical soft tissue sarcomas were also excluded, including aggressive fibromatosis, grade 1 liposarcoma, soft tissue osteosarcoma, Ewing's soft tissue sarcoma, embryonal rhabdomyosarcoma, primitive neuroectodermal tumor, dermatofibrosarcoma protuberans, and tumors of underdetermined malignant potential.

All outcome data and most clinical information were obtained from the prospectively maintained sarcoma database. Additional relevant information [patient comorbidities, American Society of Anesthesiologists (ASA) score] was obtained via chart review. ${ }^{27}$

\section{Outcomes}

Outcomes of interest included function and health status at 1-2 years following limb-preservation surgery, as well as postoperative complications.

Function The World Health Organization (WHO) International Classification of Functioning Disability and Health (ICF) served as the conceptual framework for selecting functional outcome measures. ${ }^{28}$ Impairments were measured using the Musculoskeletal Tumor Society Rating Scale (MSTS 1987), a clinician-rated scale with seven parameters. ${ }^{29}$ Each item is rated on a scale of 0-5, with a maximum score of 35 . Activity limitations were assessed using the Toronto Extremity Salvage Score (TESS), a patient-reported 30-item questionnaire that was specifically developed in patients with extremity sarcoma. ${ }^{30}$ Each item is rated on a scale of $1-5$, with the total score calculated as a percentage. Participation restrictions were measured using the self-report $\mathrm{Re}$ integration to Normal Living Index (RNL). ${ }^{31}$ The RNL was developed to assess patients' perceptions of their ability to reintegrate into their life roles and situations after 
illness or severe trauma. Its 11 items are scored on a scale of $0-10$, with a maximum of score of 110 . For all measures, higher scores represent better function.

Health Status Health status was evaluated using the patient-reported EQ5D-VAS, a visual analogue scale that measures individuals' perception of their global health state. $^{32}$ EQ5D-VAS scores range from 0 to 100 , with 100 being perfect health.

Postoperative Complications Postoperative complications were defined as any surgical complication requiring an interventional procedure (i.e., needle aspiration, incision and drainage, reoperation), any wound complication requiring deep packing for longer than 4 weeks, or any neurologic complication involving new motor deficits.

\section{Statistical Methods}

Descriptive statistics (frequencies, means, and standard deviations) were calculated for all variables. Baseline characteristics of patients in the soft tissue reconstruction and primary closure groups were compared using Student's $t$-tests for continuous variables, and chi-squared or Fisher's exact test for categorical variables. Nonparametric tests were performed when appropriate. Missing data were handled by simple $(<5 \%$ missing) or multiple imputation ( $\geq 5 \%$ missing) techniques where necessary.

Differences in postoperative MSTS (1987), TESS, RNL, and EQ5D-VAS scores between study groups were first assessed using the Wilcoxon rank-sum test. Multivariate linear regression analyses were then used to adjust for confounding in examining the association between type of wound closure and each function and health status measure. Potential confounders were identified from the literature and included: age, obesity, ASA score, baseline function and health status, tumor size, tumor grade, tumor depth, American Joint Committee on Cancer (AJCC, 5th edition) stage, tumor location, prior unplanned excision, radiotherapy, bone resection, motor nerve sacrifice, and complications. ${ }^{33}$ Multivariate models were constructed according to a method described by Harrell et al., where covariates are sequentially added to a baseline model including the key predictor (type of wound closure) and outcome. ${ }^{34}$ Covariates that changed the parameter estimate of the key predictor by $10 \%$ or more were included in the final model. Clinically important variables (age, tumor size, tumor location, baseline function/health status), determined a priori, were also retained in the final model, even if they failed to meet the above criterion. Two- and three-way interactions between type of wound closure, tumor size, and tumor location were also explored for each function and health status measure.
Differences in the proportions of patients experiencing complications in the reconstruction versus primary closure groups were compared using the chi-squared test. The relationship between type of wound closure and postoperative complications was then evaluated using multivariate logistic regression. The potential confounders of this relationship were also identified from the literature and included: age, ASA score, obesity, smoking, type II diabetes, peripheral vascular disease (PVD), tumor size, tumor location, prior unplanned excision, radiotherapy, and bone resection. The logistic regression model was also constructed according to the method of Harrell et al., as previously described. ${ }^{34}$

All statistical analyses were performed by using SAS version 9.1 (2004; SAS Institute Inc., Cary, NC).

\section{RESULTS}

\section{Patients}

Two hundred and forty-seven patients met eligibility criteria, including $56(23 \%)$ patients treated with soft tissue reconstruction and 191 (77\%) treated by primary closure. In the primary closure group, $163(85 \%)$ patients received direct wound closure and $28(15 \%)$ patients had STSG. In the reconstruction group, 40 (71\%) patients had reconstruction with pedicled flaps and $16(29 \%)$ with free flaps. Five patients required two pedicled flaps to achieve wound closure, and thus a total of 45 pedicled flaps were performed in 40 patients. The majority of flaps involved harvesting muscle (69\% myogenous, $8 \%$ myocutaneous). The most common donor sites were gastrocnemius (28\%) and latissimus dorsi (15\%).

Descriptive characteristics of the sample are provided in Table 1 . The majority of patients $(n=190,77 \%)$ were treated in Toronto and the remainder $(n=57,23 \%)$ in Montreal. Study patients were representative of patients with ESTS in that they were predominantly male, middleaged, and had deep, lower-extremity tumors. As expected, study groups also differed in terms of several baseline characteristics (Table 1). Of the 50 patients treated with radiotherapy and a flap, 49 (98\%) were irradiated preoperatively and $1(2 \%)$ postoperatively. In the primary closure group, $106(77 \%)$ patients received preoperative radiotherapy, $16(12 \%)$ received postoperative irradiation, and $15(11 \%)$ received preoperative radiotherapy with a postoperative boost. Differences in timing of radiotherapy between study groups were statistically significant $(P=0.004)$. Median length of hospitalization was also significantly longer for patients treated with flap reconstruction versus primary closure (8.0 versus 5.0 days; $P<0.0001$, Wilcoxon rank-sum test). 
TABLE 1 Descriptive characteristics of ESTS patients receiving flap reconstruction versus primary closure for extremity salvage ${ }^{\mathrm{a}}$
AJCC American Joint

Committee on Cancer, ASA

American Society of Anesthesiologists

${ }^{a}$ Values are frequencies (percentages) unless otherwise indicated. Percentages that do not add up to $100 \%$ are due to missing data or rounding

${ }^{b}$ Fisher's exact test

\begin{tabular}{|c|c|c|c|}
\hline & $\begin{array}{l}\text { Flap reconstruction } \\
(n=56)\end{array}$ & $\begin{array}{l}\text { Primary closure } \\
(n=191)\end{array}$ & $P$-value \\
\hline \multicolumn{4}{|l|}{ Sex } \\
\hline Male & $25(45 \%)$ & $116(61 \%)$ & \multirow[t]{2}{*}{0.032} \\
\hline Female & $31(55 \%)$ & $75(39 \%)$ & \\
\hline Age (years), mean $\pm S D$ & $58.2 \pm 16.7$ & $54.0 \pm 16.9$ & 0.099 \\
\hline Obese & $7(14 \%)$ & $37(23 \%)$ & 0.161 \\
\hline \multicolumn{4}{|l|}{ Smoking status } \\
\hline Current smoker & $4(7 \%)$ & $33(17 \%)$ & \multirow[t]{3}{*}{0.052} \\
\hline Ex-smoker & $11(20 \%)$ & $45(24 \%)$ & \\
\hline Nonsmoker & $28(50 \%)$ & $66(35 \%)$ & \\
\hline Type II diabetes & $4(7 \%)$ & $14(8 \%)$ & $1.0^{\mathrm{b}}$ \\
\hline Peripheral vascular disease & - & $4(2 \%)$ & $0.578^{\mathrm{b}}$ \\
\hline \multicolumn{4}{|l|}{ Presenting status } \\
\hline Primary & $53(95 \%)$ & $178(93 \%)$ & \multirow[t]{2}{*}{$1.0^{\mathrm{b}}$} \\
\hline Local recurrence & $3(5 \%)$ & $13(7 \%)$ & \\
\hline \multicolumn{4}{|l|}{ Histology } \\
\hline Malignant fibrous histiocytoma & $20(36 \%)$ & $50(26 \%)$ & \multirow{4}{*}{0.147} \\
\hline Liposarcoma & $16(29 \%)$ & $48(25 \%)$ & \\
\hline Leiomyosarcoma & $3(5 \%)$ & $31(16 \%)$ & \\
\hline Other & $17(30 \%)$ & $62(33 \%)$ & \\
\hline \multicolumn{4}{|l|}{ AJCC stage (5th edition) } \\
\hline I & $7(13 \%)$ & $45(24 \%)$ & \multirow[t]{3}{*}{0.008} \\
\hline II & $27(48 \%)$ & $108(57 \%)$ & \\
\hline III & $22(39 \%)$ & $38(20 \%)$ & \\
\hline Tumor size $(\mathrm{cm})$, mean \pm SD & $9.8 \pm 5.4$ & $7.1 \pm 6.1$ & 0.003 \\
\hline \multicolumn{4}{|l|}{ Tumor grade } \\
\hline Low & $4(7 \%)$ & $53(28 \%)$ & \multirow[t]{2}{*}{0.001} \\
\hline High & $52(93 \%)$ & $138(72 \%)$ & \\
\hline \multicolumn{4}{|l|}{ Tumor depth } \\
\hline Deep to fascia & $43(77 \%)$ & $137(72 \%)$ & \multirow[t]{2}{*}{0.454} \\
\hline Superficial to fascia & $13(23 \%)$ & $54(28 \%)$ & \\
\hline \multicolumn{4}{|l|}{ Tumor location } \\
\hline Upper extremity, proximal & $8(14 \%)$ & $32(17 \%)$ & \multirow[t]{4}{*}{0.003} \\
\hline Upper extremity, distal & $3(5 \%)$ & $21(11 \%)$ & \\
\hline Lower extremity, proximal & $22(39 \%)$ & $104(54 \%)$ & \\
\hline Lower extremity, distal & $23(41 \%)$ & $34(18 \%)$ & \\
\hline Prior excisional biopsy & $12(21 \%)$ & $83(43 \%)$ & 0.003 \\
\hline Radiotherapy & $50(89 \%)$ & $137(72 \%)$ & 0.007 \\
\hline \multicolumn{4}{|l|}{ ASA score } \\
\hline 1 & $10(19 \%)$ & $44(24 \%)$ & \multirow[t]{4}{*}{0.834} \\
\hline 2 & $27(50 \%)$ & $86(48 \%)$ & \\
\hline 3 & $15(28 \%)$ & $44(24 \%)$ & \\
\hline 4 & $2(4 \%)$ & $7(4 \%)$ & \\
\hline Bone resection & $11(20 \%)$ & $8(4 \%)$ & $0.001^{\mathrm{b}}$ \\
\hline Motor nerve resection & $12(21 \%)$ & $20(10 \%)$ & 0.032 \\
\hline Complications & $23(41 \%)$ & $60(31 \%)$ & 0.179 \\
\hline Wound related & $16(29 \%)$ & $46(24 \%)$ & 0.226 \\
\hline
\end{tabular}


TABLE 2 Preoperative and postoperative function and health status scores in ESTS patients treated with flap reconstruction versus primary closure for extremity salvage ${ }^{\mathrm{a}}$

\begin{tabular}{|c|c|c|c|}
\hline Function and health status measures & Flap reconstruction $(n=56)$ & Primary closure $(n=191)$ & $P$-value ${ }^{\mathrm{b}}$ \\
\hline \multicolumn{4}{|l|}{ Preoperative } \\
\hline MSTS (1987) & $31.6 \pm 3.8(33.0)$ & $31.5 \pm 4.0(33.0)$ & 0.895 \\
\hline TESS & $84.5 \pm 16.1(90.0)$ & $87.4 \pm 20.2(97.5)$ & 0.006 \\
\hline RNL & $86.8 \pm 24.3(96.0)$ & $97.3 \pm 18.3$ (106.9) & 0.007 \\
\hline EQ5D-VAS & $76.0 \pm 14.9(80.0)$ & $77.4 \pm 18.8(80.0)$ & 0.301 \\
\hline \multicolumn{4}{|l|}{ Postoperative measures } \\
\hline MSTS (1987) & $30.4 \pm 4.8$ (31.0) & $32.2 \pm 4.0(35.0)$ & 0.001 \\
\hline TESS & $83.3 \pm 18.7(91.4)$ & $89.5 \pm 14.9$ (95.9) & 0.007 \\
\hline RNL & $93.9 \pm 22.3(108.0)$ & $99.4 \pm 19.5$ (110.0) & 0.140 \\
\hline EQ5D-VAS & $79.3 \pm 19.8(85.0)$ & $83.0 \pm 14.7(85.0)$ & 0.450 \\
\hline
\end{tabular}

MSTS Musculoskeletal Tumor Society Rating Scale, TESS Toronto Extremity Salvage Score, RNL Re-integration to Normal Living Index, EQ5D-VAS EQ5D visual analogue scale

a Values are mean $\pm \mathrm{SD}$ (median)

b Statistical comparisons performed using the Wilcoxon rank-sum test

\section{Function and Health Status}

Univariate Analyses MSTS (1987), TESS, RNL, and EQ5D-VAS scores were negatively skewed in the study sample, and were relatively high. Table 2 presents preoperative and postoperative MSTS (1987), TESS, RNL, and EQ5D-VAS scores for each study group. At baseline, patients receiving flap reconstruction had significantly more activity limitations $(P=0.006)$ and participation restrictions $(P=0.007)$, as measured by TESS and RNL, respectively, than patients treated by primary closure. Postoperatively, patients receiving soft tissue reconstruction had significantly more impairments $(P=0.001)$ and activity limitations $(P=0.007)$, as measured by MSTS (1987) and TESS, respectively, than patients treated with primary closure. No significant differences in postoperative RNL or EQ5D-VAS scores were observed between study groups. Interactions between type of wound closure, tumor size, and tumor location were not statistically significant for any outcome measure.

Multivariate Analyses Type of wound closure (soft tissue reconstruction versus primary closure) did not significantly predict postoperative MSTS (1987), TESS, RNL, or EQ5D-VAS scores after controlling for confounding variables in multivariate regression analyses (Tables 36). Factors predictive of lower MSTS (1987) scores were large tumor size $(P=0.050)$, postoperative complications $(P=0.003), \quad$ bone resection $(P=0.034)$, baseline impairments $(P=0.001)$, and older age at definitive surgery $(P=0.0004)$ (Table 3$)$. Patients with deep tumors $(P=0.019)$, bone resection $(P=0.015)$, older age $(P=0.003)$, and more baseline activity limitations
$(P<0.0001)$ had worse postoperative TESS scores (Table 4). The only significant predictor of postoperative RNL in the multivariate model was baseline RNL $(P<0.0001)$, with the overall model explaining only $16 \%$ of the variance in RNL scores (Table 5). Finally, complications $(P=0.004)$ and lower baseline health status $(P<0.0001)$ significantly predicted lower postoperative EQ5D-VAS scores in multivariate regression analyses (Table 6).

\section{Postoperative Complications}

Univariate Analyses Postoperative complications occurred in $23(41 \%)$ patients receiving flap reconstruction and in 60 $(31 \%)$ patients treated with primary closure (Table 1$)$. The difference in proportion of complications between study groups was 0.1 [ $95 \%$ confidence interval $(\mathrm{CI}),-0.1$ to 0.2 ; $P=0.179]$.

Most complications were wound related, occurring in 16 of 23 patients (70\%) in the reconstruction group and in 46 of 60 patients $(77 \%)$ in the primary closure group $(P=0.226)$. Other specific types of complications occurred infrequently. Vascular and neurologic complications each occurred in two patients receiving flaps and five patients treated with primary closure.

There were two flap failures in the reconstruction group. Total flap necrosis occurred in one patient with a pedicled latissimus flap, who then required delayed reconstruction with the contralateral latissimus muscle. The second patient was reconstructed with a free latissimus flap and femoral vein graft, and developed intraoperative venous thrombosis resistant to heparinization; conversion to pedicled flap reconstruction was therefore required for wound closure. 
TABLE 3 Final multivariate regression model for MSTS (1987)

MSTS Musculoskeletal Tumor Society Rating Scale, AJCC American Joint Committee on Cancer (5th edition), $U E$ upper extremity, $L E$ lower extremity

a These values indicate the range of $R^{2}$ values across imputations

${ }^{b}$ Reference category: AJCC stage III

${ }^{c}$ Reference category: distal LE

TABLE 4 Final multivariate regression model for TESS

TESS Toronto Extremity Salvage Score, AJCC American Joint Committee on Cancer (5th edition), $U E$ upper extremity, $L E$ lower extremity

${ }^{a}$ These values indicate the range of $R^{2}$ values across imputations

b Reference category: AJCC stage III

c Reference category: distal LE
Outcome $=$ MSTS (1987)

$n=243$, mean $R^{2}=0.322[0.316-0.324]^{\mathrm{a}}$

$\beta(95 \% \mathrm{CI})$

$P$-value

Type of wound closure (flap versus primary closure)

$-0.4(-1.7,0.8)$

0.488

AJCC stage $\mathrm{I}^{\mathrm{b}}$

$1.2(-0.4,2.8)$

0.141

AJCC stage II $^{\mathrm{b}}$

$0.8(-0.4,2.0) \quad 0.199$

Tumor location: proximal $\mathrm{UE}^{\mathrm{c}}$

$-0.1(-1.6,1.5) \quad 0.950$

Tumor location: distal $\mathrm{UE}^{\mathrm{c}}$

$0.6(-1.2,2.5) \quad 0.504$

Tumor location: proximal $\mathrm{LE}^{\mathrm{c}}$

0.952

Tumor size $(\mathrm{cm})$

$-0.04(-1.3,1.2)$

0.049

Prior incomplete excision (no versus yes)

$-0.1(-0.2,0.0)$

0.654

Radiotherapy (no versus yes)

$-0.2(-1.3,0.8)$

0.361

Complications (no versus yes)

$0.6(-0.6,1.8)$

0.003

Bone resection (no versus yes)

$1.6(0.6,2.7)$

0.034

Motor nerve resection (no versus yes)

0.267

Baseline MSTS

$2.1(0.2,4.1)$

0.001

Age (years)

0.0004

\begin{tabular}{|c|c|c|}
\hline $\begin{array}{l}\text { Outcome }=\text { TESS } \\
n=235, \text { mean } R^{2}=0.349[0.333-0.364]^{\mathrm{a}}\end{array}$ & $\beta(95 \% \mathrm{CI})$ & $P$ value \\
\hline Type of wound closure (flap versus primary closure) & $-0.8(-5.5,3.9)$ & 0.731 \\
\hline AJCC stage $I^{\mathrm{b}}$ & $-2.4(-9.2,4.5)$ & 0.500 \\
\hline AJCC stage II $^{\mathrm{b}}$ & $1.3(-3.6,6.1)$ & 0.609 \\
\hline Tumor grade (high versus low) & $-2.1(-6.9,2.7)$ & 0.386 \\
\hline Tumor location: proximal $\mathrm{UE}^{\mathrm{c}}$ & $0.4(-5.5,6.3)$ & 0.889 \\
\hline Tumor location: distal $\mathrm{UE}^{\mathrm{c}}$ & $3.0(-4.0,10.1)$ & 0.401 \\
\hline Tumor location: proximal $\mathrm{LE}^{\mathrm{c}}$ & $-0.4(-5.1,4.4)$ & 0.883 \\
\hline Tumor depth (superficial versus deep) & $5.8(0.9,10.6)$ & 0.019 \\
\hline Tumor size $(\mathrm{cm})$ & $-0.2(-0.5,0.2)$ & 0.331 \\
\hline Prior incomplete excision (no versus yes) & $1.5(-2.7,5.7)$ & 0.481 \\
\hline Radiotherapy (no versus yes) & $3.5(-1.5,8.4)$ & 0.167 \\
\hline Complications (no versus yes) & $3.5(-0.5,7.6)$ & 0.088 \\
\hline Bone resection (no versus yes) & $8.6(1.7,15.5)$ & 0.015 \\
\hline Motor nerve resection (no versus yes) & $1.9(-3.8,7.6)$ & 0.514 \\
\hline Baseline TESS & $0.3(0.2,0.4)$ & $<0.0001$ \\
\hline Age (years) & $-0.2(-0.3,-0.1)$ & 0.003 \\
\hline
\end{tabular}

Donor-site complications occurred in three patients with free flaps, including two seromas and one infection. No patients in the primary closure group required secondary flap reconstruction to achieve stable soft tissue coverage.

Eight patients (14\%) in the soft tissue reconstruction group and 17 patients (9\%) in the primary closure group required reoperation for a complication. The difference in proportion of reoperations between study groups was 0.1 (95\% CI, -0.2 to $0.3 ; P=0.567$ ). Only one patient (in the primary closure group) required amputation secondary to a complication.
Multivariate Logistic Regression Type of wound closure did not significantly predict postoperative complications when adjusting for confounders in logistic regression analysis (Table 7). Tumor size $(P=0.003)$, radiotherapy $(P=0.025)$, bone resection $(P=0.010)$, and patient age $(P=0.013)$ were significant predictors of complications in the multivariate model. Patients treated with radiotherapy and bone resection were 2.7 and 4.1 times more likely to have a complication, respectively. For each $1-\mathrm{cm}$ increase in tumor size and 5-year increase in age, the odds of a complication increased by $8 \%$ and $10 \%$, respectively. 
TABLE 5 Final multivariate regression model for RNL

$R N L$ Re-integration to Normal Living Index, AJCC American Joint Committee on Cancer (5th edition), $U E$ upper extremity, $L E$ lower extremity

a These values indicate the range of $R^{2}$ values across imputations

${ }^{b}$ Reference category: AJCC stage III

c Reference category: distal LE

\begin{tabular}{|c|c|c|}
\hline $\begin{array}{l}\text { Outcome }=\mathrm{RNL} \\
n=232, \text { mean } R^{2}=0.158[0.149-0.173]^{\mathrm{a}}\end{array}$ & $\beta(95 \% \mathrm{CI})$ & $P$-value \\
\hline Type of wound closure (flap versus primary closure) & $2.4(-4.5,9.3)$ & 0.491 \\
\hline AJCC stage $I^{\mathrm{b}}$ & $1.4(-8.1,10.8)$ & 0.778 \\
\hline AJCC stage II $^{\mathrm{b}}$ & $3.0(-3.7,9.7)$ & 0.384 \\
\hline Tumor grade (high versus low) & $-4.8(-11.7,2.0)$ & 0.164 \\
\hline Tumor location: proximal $\mathrm{UE}^{\mathrm{c}}$ & $3.7(-4.7,12.0)$ & 0.394 \\
\hline Tumor location: distal $\mathrm{UE}^{\mathrm{c}}$ & $7.7(-2.2,17.7)$ & 0.127 \\
\hline Tumor location: proximal $\mathrm{LE}^{\mathrm{c}}$ & $4.4(-2.5,11.3)$ & 0.207 \\
\hline Tumor size $(\mathrm{cm})$ & $-0.2(-0.7,0.3)$ & 0.429 \\
\hline Prior incomplete excision (no versus yes) & $-0.5(-6.5,5.5)$ & 0.865 \\
\hline Radiotherapy (no versus yes) & $3.1(-3.7,9.8)$ & 0.368 \\
\hline Complications (no versus yes) & $2.8(-3.0,8.5)$ & 0.346 \\
\hline Bone resection (no versus yes) & $1.3(-8.5,11.0)$ & 0.800 \\
\hline Baseline RNL & $0.3(0.2,0.4)$ & $<0.0001$ \\
\hline Age (years) & $-0.1(-0.3,0.0)$ & 0.128 \\
\hline
\end{tabular}

TABLE 6 Final multivariate regression model for EQ5DVAS

EQ5D-VAS EQ5D visual analogue scale, AJCC American Joint Committee on Cancer (5th edition), $U E$ upper extremity, $L E$ lower extremity

a These values indicate the range of $R^{2}$ values across imputations

b Reference category: distal LE

TABLE 7 Predictors of postoperative complications in logistic regression analysis (imputed data, $n=247$ )

AJCC American Joint Committee on Cancer (5th edition), $O R$ odds ratio

\begin{tabular}{lcc}
\hline $\begin{array}{l}\text { Outcome }=\mathrm{EQ} 5 \mathrm{D}-\mathrm{VAS} \\
n=224, \text { mean } R^{2}=0.165[0.152-0.179]^{\mathrm{a}}\end{array}$ & $\beta$-value \\
\hline Type of wound closure (flap versus primary closure) & $-1.0(-6.3,4.4)$ & 0.722 \\
Tumor grade (high versus low) $^{\mathrm{b}}$ & $-0.6(-5.6,4.4)$ & 0.813 \\
Tumor location: proximal UE $^{\mathrm{b}}$ & $-0.9(-7.5,5.7)$ & 0.783 \\
Tumor location: distal UE $^{\mathrm{b}}$ & $3.1(-5.1,11.4)$ & 0.456 \\
Tumor location: proximal LE $^{\mathrm{b}}$ & $0.2(-5.3,5.7)$ & 0.951 \\
Tumor size (cm) $_{\text {Prior incomplete excision (no versus yes) }}$ & $0.0(-0.4,0.4)$ & 0.934 \\
Radiotherapy (no versus yes) & $-0.4(-5.1,4.2)$ & 0.858 \\
Complications (no versus yes) & $0.9(-4.3,6.1)$ & 0.732 \\
Baseline EQ5D-VAS & $6.6(2.1,11.0)$ & 0.004 \\
Age (years) & $0.3(0.2,0.4)$ & $<0.0001$ \\
\hline
\end{tabular}

\begin{tabular}{llc}
\hline Outcome $=$ complications & Adjusted OR (95\% CI) & $P$-value \\
\hline Flap reconstruction versus primary closure & $0.78(0.39,1.58)$ & 0.488 \\
Tumor size $(\mathrm{cm})$ & $1.08(1.03,1.14)$ & 0.003 \\
AJCC stage II versus I & $1.36(0.58,3.18)$ & 0.482 \\
AJCC stage III versus I & $1.28(0.47,3.50)$ & 0.631 \\
Prior incomplete excision (yes versus no) & $0.84(0.44,1.61)$ & 0.604 \\
Radiotherapy (yes versus no) & $2.67(1.13,6.27)$ & 0.025 \\
Bone resection (yes versus no) & $4.06(1.40,11.74)$ & 0.010 \\
Age (years) & $1.02(1.01,1.04)$ & 0.013 \\
\hline
\end{tabular}

\section{DISCUSSION}

This study is the first to directly compare function and health status outcomes between patients receiving soft tissue reconstruction and primary closure for limb preservation in ESTS. Patients in the flap reconstruction group demonstrated significantly more impairments and activity limitations at 1-2 years postoperatively than patients in the primary closure group. A number of factors may contribute to this finding. Patients receiving flaps had 
significantly larger and higher-grade tumors than patients treated with primary closure, and were more likely to have received preoperative irradiation, bone resection, and motor nerve resection. Each of these tumor and treatment factors has been associated with worse function and/or health status outcomes in at least one prior study of ESTS patients undergoing limb-salvage surgery. ${ }^{19,25,35,36}$ Additionally, patients in the reconstruction group had more preoperative activity limitations.

Considering these risk factors for poor functional outcome, it is perhaps surprising that postoperative MSTS (1987) and TESS scores in patients requiring extremity reconstruction were not substantially worse. Also interesting is the fact that patients requiring reconstructive surgery in this study reported similar participation (RNL) and health status (EQ5D-VAS) outcomes to patients treated with primary closure. This finding suggests that patients with reconstructed extremities are able to maintain similar social and occupational functioning and overall well-being compared with patients not requiring reconstructive surgery, despite greater restrictions in the physical and activity domains of function.

In fact, postoperative MSTS (1987), TESS, RNL, and EQ5D-VAS scores were relatively high in both study groups and compare favorably with those reported previously. Serletti et al. reported a mean MSTS (1987) score of 28.4, and Nelson et al. reported an average TESS score of 81 , in 20 and 34 extremity sarcoma patients treated with limb salvage and reconstruction, respectively. ${ }^{22,24}$ Participation and health status outcomes have not been previously examined in ESTS patients requiring soft tissue reconstruction. In larger studies where the majority of patients were treated with simple wound closure techniques, MSTS (1987) scores range from 27.5 to 31.4 , TESS scores range from $83 \%$ to $89 \%$, RNL scores average 98.7 , and EQ5DVAS scores average $80.5 .^{19,25,35,37-39}$ The fact that patients requiring soft tissue reconstruction demonstrated good function and health status outcomes in this study supports the value of limb-salvage approaches in these difficult cases.

This study is also the first to investigate the role of reconstructive surgery in influencing function and health status outcomes in extremity sarcoma. In this study, type of wound closure did not significantly predict postoperative impairments, activity limitations, participation restrictions, or health status after adjusting for confounding in multivariate regression analyses. Importantly, the confidence intervals for the adjusted differences (regression coefficients) in MSTS (1987), TESS, RNL, and EQ5D-VAS scores between the reconstruction and primary closure groups also exclude clinically meaningful differences in these outcome measures, based on what is currently known regarding their measurement properties. ${ }^{26,30-32,35,40}$ Thus, in spite of the frequent use of myogenous and myocutaneous flaps in this study, flap reconstruction did not impair function and health status outcomes in patients undergoing limb salvage for ESTS.

Other factors predictive of impairments, activity limitations, and health status in this study are generally consistent with prior literature. Large tumor size, complications, bone resection, and older age have negatively impacted postoperative MSTS (1987) scores in prior studies of ESTS patients undergoing limb salvage. ${ }^{19,25,35}$ Along the same lines, deep tumors and bone resection have been previously associated with lower TESS scores, and complications have been significantly correlated with lower EQ5D-VAS scores. ${ }^{19,36,39}$ There are also important differences between the findings of this study and the literature, which may in part be explained by differences in patient population, method of multivariate model building, definition of predictor variables, selection of outcome measures, or lack of adjustment for baseline function/ health status. For example, some studies have not found an association between age and MSTS (1987) or TESS, but have found an association between motor nerve resection and more impairments and activity limitations. ${ }^{19,25,35,36,38}$

Participation restrictions, as measured by RNL, are an important aspect of patient-reported quality of life that have been underinvestigated in ESTS. ${ }^{39,41}$ The only significant determinant of postoperative RNL score in this study was preoperative RNL score. Schreiber et al. similarly found the number of preexisting comorbid conditions to be the only significant correlate of postoperative RNL score in a retrospective study of 100 ESTS patients. ${ }^{39}$ These findings suggest that other, unmeasured factors are influencing postoperative participation restrictions. Indeed, studies in other populations have suggested that social support, socioeconomic status, cognition, and emotional well-being are important determinants of participation outcome. ${ }^{41-45}$ These factors need to be explored in future studies of ESTS.

A secondary outcome of this study was postoperative complications. Patients receiving flap reconstruction had more complications than patients treated with primary closure in this study (41\% of 56 versus $31 \%$ of 191 ). Although not statistically significant, this $10 \%$ difference in complications has clinical significance for patients with ESTS. Lohman et al. and Cannon et al. similarly found an approximately $10 \%$ higher incidence of complications in patients receiving soft tissue reconstruction. ${ }^{16,46}$ Two other studies reported equivalent rates of complications in patients treated with reconstruction and primary closure. ${ }^{17,47}$ However, both of these studies included patients receiving skin grafts and/or complex primary closures in their reconstruction group. Not only are these procedures less morbid, but patients receiving skin grafts and complex 
primary closures are likely to have less adverse tumor and treatment characteristics than patients requiring flaps. Yet another study reported fewer complications in patients receiving flaps versus primary closure, but the very small sample sizes in this comparison limit interpretation of this finding. ${ }^{48}$

An important question is whether the increased complications in patients receiving soft tissue reconstruction in this study is due to additional flap-related morbidity or due to other characteristics of patients receiving flaps for limb salvage. In support of the latter, patients receiving flap reconstruction had a number of identified risk factors for increased complications in ESTS, including large tumor size, preoperative irradiation, and bone resection. ${ }^{17,46,48-51}$ Furthermore, soft tissue reconstruction was not an independent predictor of complications in multivariate logistic regression analyses. This finding agrees with that of O'Sullivan et al., although these authors did include skin grafting as part of their reconstruction group. ${ }^{17}$ Importantly, neither this study nor that of O'Sullivan et al. had sufficient numbers of subjects to evaluate the impact of soft tissue reconstruction on complications in logistic regression analyses while accounting for all potentially important confounders, and so these results must be viewed as preliminary and interpreted with caution. ${ }^{17}$

The main limitations of this study lie in its generalizability and retrospective design. The patients in this study were treated at the two largest specialty adult sarcoma centers in Canada (Montreal and Toronto). Given that care for individuals with sarcoma in Canada is routinely provided in a tertiary oncology setting, the patients seen at the sarcoma centers in this study should represent those presenting to centers across Canada. However, the centers in Toronto and Montreal that contributed to the study database have similar treatment protocols wherein chemotherapy is not routine care for individuals with ESTS. Considering the potential impact of chemotherapy on function, health status, and complications in ESTS, the findings of this study may not be generalizable to ESTS patients treated routinely with (neo)adjuvant chemotherapy. Selection bias related to exposure group classification is also a concern in this study, as highlighted by the significant differences in baseline characteristics between study groups. However, in using multivariate regression analyses to adjust for important confounders, identified a priori from the literature and clinical expertise, and in large part measured prospectively, best efforts were made to minimize treatment selection bias in these analyses.

In conclusion, this study provides new and important information for the multidisciplinary sarcoma team to improve patient education and better manage patients' expectations regarding their recovery. First, patients who require reconstructive surgery for limb preservation can achieve good functional outcomes. Based on the results of this study, surgeons can expect that patients with reconstructed extremities may have more impairments and activity limitations relative to patients treated with simple wound closure techniques following tumor ablation. However, this may not translate into worse participation or health status outcomes. Third, reconstructive approaches centered mainly on muscle-bearing flaps do not adversely affect 1-2-year function or health status outcomes relative to primary wound closure techniques. This is an important point considering recent trends towards use of more technically challenging, free perforator flaps for extremity reconstruction. Furthermore, while complication rates may be higher in patients requiring reconstructive surgery, surgical flaps themselves do not appear to either increase or decrease wound complications in this population. However, prospective studies are warranted to better assess the risk-benefit profile of soft tissue reconstruction in regard to postoperative complications, considering that this and prior studies have been underpowered to thoroughly evaluate this association. Taken together, the findings of this study reinforce the value of flap reconstruction in the management of extremity soft tissue sarcoma, both to achieve limb preservation and to reduce the morbidity of limb-salvage procedures in difficult cases.

ACKNOWLEDGMENT In conducting this research, the primary author was supported by a Master's Award from the Canadian Institutes of Health Research and by the Department of Surgery at the University of Toronto. The authors also thank Dr. Peter Ferguson, Dr. Robert Turcotte, and Dr. Robert Bell for their contribution of study patients and clinical material.

\section{REFERENCES}

1. Tukiainen E, Bohling T, Huuhtanen R. Soft tissue sarcoma of the trunk and extremities. Scand J Surg. 2003;92:257-63.

2. American Cancer Society: detailed guide: Sarcoma-Adult Soft Tissue Cancer. http://www.cancer.org. Accessed 3 Nov 2008.

3. Abbas JS, Holyoke ED, Moore R, Karakousis CP. The surgical treatment and outcome of soft tissue sarcoma. Arch Surg. 1981;116:765-9.

4. Ferguson PC. Surgical considerations for management of distal extremity soft tissue sarcomas. Curr Opin Oncol. 2005;17:366-9.

5. Stinson SF, DeLaney TF, Greenberg J, et al. Acute and long term effects of combined modality limb-sparing therapy for extremity soft tissue sarcoma. Int J Radiat Oncol Biol Phys. 1991;21:14939.

6. Lindberg RD, Martin RG, Romsdahl MM, Barkley HT Jr. Conservative surgery and postoperative radiotherapy in 300 adults with soft-tissue sarcomas. Cancer. 1981;47:2391-7.

7. Leibel SA, Tranbaugh RF, Wara WM, Beckstead JH, Bovill EG, Phillips TL. Soft tissue sarcoma of the extremities: Survival and patterns of failure with conservative surgery and post-operative irradiation compared to surgery alone. Cancer. 1982;50: 1076-83.

8. Gustafson P, Arner M. Soft tissue sarcoma of the upper extremity: descriptive data and outcome in a population-based series of 108 patients. J Hand Surg Am. 1999;24:668-74. 
9. DeLaney TF, Spiro IJ, Suit HD, et al. Neoadjuvant chemotherapy and radiotherapy for large extremity soft-tissue sarcomas. Int $J$ Radiat Oncol Biol Phys. 2003;56:1117-27.

10. Spiro IJ, Gebhardt MC, Jennings LC, Mankin HJ, Harmon DC, Suit HD. Prognostic factors for local control of sarcomas of the soft tissues managed by radiation and surgery. Semin Oncol. 1997;24:540-6.

11. Cordeiro PG, Neves RI, Hidalgo DA. The role of free tissue transfer following oncologic resection in the lower extremity. Ann Plast Surg. 1994;33:9-16.

12. Heller L, Levin LS. Lower extremity microsurgical reconstruction. Plast Reconstr Surg. 2001;108:1029-41.

13. Popov P, Tukiainen E, Asko-Seljaavaara S, Huuhtanen R, Virolainen M, Virkkunen P, et al. Soft tissue sarcomas of the lower extremity: surgical treatment and outcome. Eur J Surg Oncol. 2000;26:679-85.

14. Clark MA, Fisher C, Judson I, Thomas JM. Soft-tissue sarcomas in adults. NEJM 2005;353:701-11.

15. Carlson GW. The evolution of extremity reconstruction for soft tissue sarcoma. Ann Surg Oncol. 2006;13:610-1.

16. Lohman RF, Nabawi AS, Reece GP, Pollock RE, Evans GR. Soft tissue sarcoma of the upper extremity: a 5-year experience at two institutions emphasizing the role of soft tissue flap reconstruction. Cancer 2002;94:2256-64.

17. O'Sullivan B, Davis AM, Turcotte R, et al. Preoperative versus postoperative radiotherapy in soft tissue reconstruction of the limbs: a randomized trial. Lancet. 2002;359:2235-41.

18. Kim JY, Youssef A, Subramanian V, Rogers BA, Pollock RE, Robb GL, et al. Upper extremity reconstruction following resection of soft tissue sarcomas: a functional outcomes analysis. Ann Surg Oncol. 2004;11:921-7.

19. Davis AM, Sennik S, Griffen AM, Wunder JS, O'Sullivan B, Catton $\mathrm{CN}$, et al. Predictors of functional outcomes following limb salvage surgery for lower-extremity soft tissue sarcoma. J Surg Oncol. 2000;73:206-11.

20. Lampert MH, Gerber LH, Glatstein E, Rosenberg SA, Danoff JV. Soft tissue sarcoma: functional outcome after wide local excision and radiation therapy. Arch Phys Med Rehabil. 1984;65:477-80.

21. Robinson MH, Spruce L, Eeles R, Fryatt I, Harmer CL, Thomas $\mathrm{JM}$, et al. Limb function following conservation treatment of adult soft tissue sarcoma. Eur J Cancer. 1991;27:1567-74.

22. Serletti J, Carras A, O'Keefe RJ, Rosier RN. Functional outcome after soft-tissue reconstruction for limb salvage sarcoma surgery. Plast Reconstr Surg. 1998;102:1576-83.

23. Rivas B, Carrillo JF, Onate-Ocana LF. Functional evaluation after reconstruction with myocutaneous and fasciocutaneous flaps for conservative oncologic surgery of the extremities. Ann Surg Oncol. 2006;13:721-7.

24. Nelson AA, Frassica FJ, Gordon TA, Deune EGL. Cost analysis of functional restoration surgery for extremity soft-tissue sarcoma. Plast Reconstr Surg. 2006;117:277-83.

25. Bell RS, O’Sullivan B, Davis A, Langer F, Cummings B, Fornasier VL. Functional outcome in patients treated with surgery and irradiation for soft tissue tumors. J Surg Oncol. 1991;48: 224-31.

26. Davis AM, Bell RS, Badley EM, Yoshida K, Williams JI. Evaluating functional outcome in patients with lower extremity sarcoma. Clin Orthop. 1999;358:90-100.

27. American Society of Anesthesiologists. ASA Physical Status Classification System. http://www.asahq.org/clinical/physical status.htm. Accessed 3 Mar 2009.

28. World Health Organization. International classification of functioning, disability, and health: ICF. Geneva: World Health Organization; 2001.

29. Enneking WF. Modification of the system for functional evaluation in the surgical management of musculoskeletal tumors. In:
Enneking WF (editor) Limb salvage in musculoskeletal oncology. New York: Churchill-Livingston; 1987. pp 626-39.

30. Davis AM, Wright JG, Williams JI, Bombardier C, Griffin A, Bell RS. Development of a measure of physical function for patients with bone and soft tissue sarcomas. Qual Life Res. 1996;5:508-16.

31. Wood-Dauphine SL, Opzoomer MA, Williams JI, Marchand B, Spitzer WO. Assessment of global function: the Re-integration to Normal Living Index. Arch Phys Med Rehab. 1988;6:583-90.

32. Brooks R, Rabin R, de Charro F (editors) The measurement and valuation of health status using EQ-5D: a European perspective. Boston: Kluwer Academic; 2003.

33. Fleming ID, Cooper JS, Henson DE, et al. (eds). AJCC cancer staging manual. 5th ed. Philadelphia: Lippincott, 1997.

34. Harrell FE. Regression modeling strategies. New York: SpringerVerlag; 2001.

35. Davis AM, O'Sullivan B, Bell RS, et al. Function and health status outcomes in a randomized trial comparing preoperative and postoperative radiotherapy in extremity soft tissue sarcoma. J Clin Oncol. 2002;20:4472-7.

36. Gerrand $\mathrm{CH}$, Wunder JS, Kandel RA, et al. The influence of anatomic location on function outcome in lower-extremity softtissue sarcoma. Ann Surg Oncol. 2004;11:476-82.

37. Colterjohn NR, Davis AM, O'Sullivan B, Catton CN, Wunder JS, Bell RS. Functional outcome in limb-salvage surgery for soft tissue tumors of the foot and ankle. Sarcoma. 1997;1:67-74.

38. Wright EH, Gwilym S, Gibbons CL, Critchley P, Giele HP. Functional and oncological outcomes after limb-salvage surgery for primary sarcomas of the upper limb. J Plast Reconstr Aesthet Surg. 2008;61:382-7.

39. Schreiber D, Bell RS, Wunder JS, O'Sullivan B, Turcotte R, Masri BA, Davis AM. Evaluation function and health-related quality of life in patients treated for extremity soft tissue sarcoma. Qual Life Res. 2006;15:1439-46.

40. Pickard AS, Neary MP, Cella D. Estimation of minimally important differences in EQ5D-utility and VAS scores in cancer. Health Qual Life Outcomes. 2007;5:70-8.

41. Harwood RH, Prince M, Mann A, Ebrahim S. Associations between diagnoses, impairments, disability and handicap in a population of elderly people. Int J Epidemiol. 1998;27:261-8.

42. Jette AM, Keysor J, Coster W, Ni P, Haley S. Beyond function: predicting participation in a rehabilitation cohort. Arch Phys Med Rehabil. 2005;86:2087-94.

43. Wilkie R, Peat G, Thomas E, Croft P. Factors associated with participation restriction in community-dwelling adults aged 50 years and over. Qual Life Res. 2007;16:1147-56.

44. Cardol M, de Jong BA, van den Bos GA, Beelem A, de Groot IJ, de Haan RJ. Beyond disability: perceived participation in people with a chronic disabling condition. Clin Rehabil. 2002;16:27-35.

45. Sturm JW, Donnan GA, Dewey HM, Macdonell RA, Gilligan AK, Thrift AG. Determinants of handicap after stroke: the North East Melbourne stroke incidence study (NEMESIS). Stroke. 2004;35;715-20.

46. Cannon CP, Ballo MT, Zagars GK, et al. Complications of combined modality treatment of primary lower extremity softtissue sarcomas. Cancer. 2006;107:2455-61.

47. Tseng JF, Ballo MT, Langstein HN, et al. The effect of preoperative radiotherapy and reconstructive surgery on wound complications after resection of extremity soft-tissue sarcomas. Ann Surg Oncol. 2006;13:1209-15.

48. Peat BG, Bell RS, Davis A, et al. Wound-healing complications after soft-tissue sarcoma surgery. Plast Reconstr Surg. 1994; 93:980-7.

49. Geller DS, Hornicek FJ, Mankin HJ, Raskin KA. Soft tissue sarcoma resection volume associated with wound-healing complications. Clin Orthop Rel Res. 2007;459:182-5. 
50. Saddegh MK, Bauer HC. Wound complication in surgery of soft tissue sarcoma: analysis of 103 consecutive patients managed without adjuvant therapy. Clin Orthop Rel Res. 1993;289: 247-53.
51. Bell RS, O'Sullivan B, Langer F, et al. Complications and functional results after limb-salvage surgery and radiology for difficult mesenchymal neoplasms: a prospective analysis. Can $J$ Surg. 1989;32:69-73. 